\title{
Outcome of Treatment of Giant-Cell Tumor of Bone: A Single-Institutional Retrospective Study
}

\author{
Mahmoud A. Elshenawy 1, 2, Ahmed Badran 1, 3, Ayman Elshentenawy 1, 4, Abdelmonem \\ Eldali $^{5}$, Muhammad Memon ${ }^{1}$
}

${ }^{1}$ Medical Oncology Section, Oncology Centre, King Faisal Specialist Hospital and Research Centre, Riyadh, Saudi Arabia; ${ }^{2}$ Clinical Oncology and Nuclear Medicine Department, Faculty of Medicine, Menoufia University, Shebin El Kom, Egypt; ${ }^{3}$ Clinical Oncology Department, Faculty of Medicine, Ain Shams University, Cairo, Egypt; ${ }^{4}$ Kasr El-Aini Centre of Clinical Oncology and Nuclear Medicine (NEMROCK), Faculty of Medicine, Cairo University, Cairo, Egypt; 5 Department of Biostatistics, Epidemiology and Scientific Computing, King Faisal Specialist Hospital and Research Centre, Riyadh, Saudi Arabia

Background: Giant-cell tumor of bone (GCTB) is a locally aggressive tumor which metastasizes infrequently to the lungs. The standard treatment of GCTB was surgery until the approval of denosumab.

Aim: To describe the outcome of treatment of this rare tumor and to determine factors that influence survival.

Methods: Retrospective review of the medical records of GCTB patients treated at our institution. Collected data includes: clinicopathological data, treatment modalities and possible prognostic factors.

Results: Forty-two patients were identified between May 2008 and November 2017. Their median age was 31 years, and the majority (62\%) were females. The commonest primary sites were the upper and lower limbs $(50 \%$ and $43 \%$, respectively). Eight $(19 \%)$ patients initially presented with lung metastases. Thirteen $(31 \%)$ patients received denosumab as first line treatment before surgery and 12 of them underwent surgery post-denosumab. Denosumab was given after recurrence in $12(29 \%)$ patients [8 (19\%) with lung metastasis and $4(10 \%)$ with localized disease]. The objective response rate to denosumab after recurrence was 50\%. Four (10\%) patients achieved complete response and $2(5 \%)$ partial response. After a median follow up of 4.7 years, $6(14 \%)$ patients had local recurrence and $8(19 \%)$ had lung metastasis with no recorded deaths. The 5-year progression-free survival rate was $61 \%$.

Conclusion: Denosumab is effective and tolerable in the management of GCTB preoperatively in localized disease to facilitate surgery and in the management of metastatic disease. Multi-institutional prospective studies are needed for further assessment.

Keywords: Denosumab. Giant-cell tumor of bone. Prognosis. Metastatic

Corresponding Author: Mahmoud A. Elshenawy, MD; Section of Medical Oncology, Oncology Center, King Faisal Specialist Hospital \& Research Center, PO Box 3354, Riyadh 11211, Saudi Arabia. Email: melshenawy@kfshrc.edu.sa Submitted: 15-January-2019, Revised: 26-January-2019, Accepted: 28-January-2019, Published online: 1-Fibruary-2019

\section{INTRODUCTION}

Giant-cell tumor of bone (GCTB) is characterized by the presence of multinucleated osteoclast-like (OCLlike) giant cells. Also, it has uncontrolled proliferation of mesenchymal stromal cells due to sustained osteoclastogenesis and failure of differentiation into osteoblasts ${ }^{1,2}$.

In general, these tumors are rare. A populationbased study from Sweden found an incidence rate of 1.3 per million persons per year ${ }^{3}$. The incidence of GCTB in Asian countries is significantly higher than that in western countries ${ }^{4,5}$. It is more common in the 20 s and 30 s age groups and there is a slight female predominance $3,6-8$

Although GCTB is classified as benign with aggressive destructive local activity, it exhibits a possible metastatic potential upon recurrence ${ }^{7,9-11}$. Lung metastases have been reported in up to $3 \%$ of the cases ${ }^{9}$, 11-13. Breast tissue may be a possible, yet extremely rare, metastatic location for GCTB ${ }^{13}$.

Surgery has been the cornerstone treatment of GCTB, especially for resectable tumors of upper and lower limbs. However, for patients with potentially resectable GCTB or for whom initial surgery would be associated with unacceptable functional compromise or significant morbidity, radiotherapy may be considered ${ }^{14}$. The long-term local control rate has been reported to range from $60 \%$ to $84 \%{ }^{15,16}$. Because of the possibility of radiation-induced sarcoma, it is not a favorable option for treatment of GCTB ${ }^{17}$.

Chemoembolization has been a treatment of choice for sacral tumors with long-term control of the disease; however, due to the small numbers, it is unclear whether intra-arterial cisplatin has an additional benefit or not ${ }^{15}$. 
In GCTB, the stromal cells and OCL-like giant cells express receptor activator of nuclear factor kappa$B$ ligand (RANKL) and receptor activator of nuclear factor kappa-B (RANK), respectively, and the RANKRANKL interaction plays a major role in the differentiation and activation of osteoclasts ${ }^{18}$. Therefore, the RANK-RANKL interaction has a critical role for bone destruction in GCTB, and a dramatic change was observed after treatment with denosumab. Multinucleated OCL-like giant cells and stromal cells were decreased after denosumab treatment for GCTB ${ }^{19}$.

In June 2013, the US Food and Drug Administration (FDA) approved denosumab for the treatment of unresectable GCTB or when there is a possibility of mutilating surgery. Approval was based on a review of data from 305 adult or adolescent patients who had locally advanced GCTB treated in two clinical trials. A reduction in tumor size was observed in 47 out of 187 patients who had measurable disease after an average of 3 months treatment with denosumab, and regrowth was observed in only 3 patients after an average follow up period of 20 months 20,21

The optimal duration of preoperative denosumab is not yet established, and the timing of surgery is usually based on the rate of repair detected radiologically. Patients are typically treated for around six months ${ }^{22}$. The value of adjuvant denosumab after surgery to decrease local recurrence is not yet known and is the subject of debate ${ }^{23}$.

Data about the management of GCTB from the Middle East are lacking. We reviewed the outcome of treatment of GCTB in our tertiary care center that might represent a real-world experience from this region of the world.

\section{METHODS}

The medical records of all patients with the diagnosis of GCTB treated at our institution in the period between May 2008 and November 2017 were retrospectively reviewed. The aim of this study was to determine the outcome of treatment of this rare tumor and to determine factors that might affect survival. Patients were considered eligible if they had histologically confirmed GCTB.

This study was approved by our Institutional Review Board (IRB) of King Faisal Specialist Hospital and Research Center - Riyadh (approval \# 2161166).

Demographic data, different treatment modalities including denosumab, response rate, disease progression, and survival data were collected. Denosumab was approved in our institution as a standard of care in management of patients with advanced GCTB since June 2013. The schedule used to date in our routine practice is denosumab $120 \mathrm{mg}$ subcutaneously every 28 days, with two additional loading doses on days 8 and 15 of the first month.

Response was assessed retrospectively according to the revised response evaluation criteria in solid tumors (RECIST) v1.1 24 .
Progression-free survival (PFS) was calculated from the date of starting treatment till the date of progression or death. Patients who were lost to follow up were censored at the date of their last follow up.

Progression-free survival was analyzed according to gender, body mass index (BMI), site and size of primary tumor, preoperative denosumab, post-surgical recurrence, site of recurrence and post-recurrence denosumab. Because no deaths were recorded at the time of data analysis, overall survival couldn't be calculated.

Statistical analysis was done using the software package SAS version 9.4 (SAS Institute Inc., Cary, NC, USA). Descriptive statistics for the continuous variables were reported as mean $\pm 95 \%$ confidence interval (CI) and categorical variables were summarized as frequencies and percentages. Continuous variables were compared by Student's t-test or ANOVA as appropriate; while categorical variables were compared by Chisquare test. Kaplan-Meyer method was used in survival tables and curves and the different subgroups were compared by the log-rank test. Cox regression model was used for multivariate analysis using factors that were significant in univariate analysis or those with $p$ value of $\leq 0.2$. The level of statistical significance was set at $\mathrm{p}$-value $<0.05$.

\section{RESULTS}

Forty-two patients with the diagnosis of GCTB were identified during the specified time period. The median age was 31.1 years, and the majority of patients (61.9\%) were females. The median size of primary tumors was $11.5 \mathrm{~cm}$ (range: 1.5-16). The most common sites of the primary tumor were in upper and lower limbs $(50 \%$ and $42.9 \%$, respectively). Eight (19\%) patients presented initially with lung metastasis. The baseline characteristics of the study population are detailed in table 1 .

Thirteen $(31 \%)$ patients received denosumab as first line treatment before surgery. The median number of pre-surgical denosumab doses was 9 (range: 4-10). Twelve $(28.5 \%)$ patients underwent surgery; 8 of them had partial response (PR) and 4 had stable disease (SD). Disease progression (PD) was noticed in 1 (2.4\%) patient who was exempted from surgery.

Forty-one $(98 \%)$ patients underwent surgery. The type of surgery was wide or enbloc resection in 27 $(64 \%)$ patients and intralesional curettage in $14(33 \%)$.

Denosumab was given after recurrence in 12 (28.6\%) patients [8 $(19 \%)$ patients with lung metastasis and $4(9.6 \%)$ patients with localized disease]. The median number of post-recurrence denosumab doses was 5 (range: 4-10). The overall response rate (ORR) to denosumab after recurrence was $50 \%$ with complete remission (CR) in $4(9.6 \%)$ patients and PR in $2(4.8 \%)$.

As of November 2017, the median follow up period was 4.7 years (range: $0.3-8.9$ ) and 14 (33\%) patients experienced recurrence including local recurrence in 6 $(14 \%)$ and lung metastasis in $8(19 \%)$. No deaths were recorded. 
Table 1: Characteristics and treatment of 42 patients with giant cell tumor of bone

\begin{tabular}{|c|c|c|}
\hline & No. & $\%$ \\
\hline \multicolumn{3}{|l|}{ Age at diagnosis (years) } \\
\hline Median & \multicolumn{2}{|c|}{$31.1(15.8-57.7)$} \\
\hline Mean & \multicolumn{2}{|c|}{32.3} \\
\hline \multicolumn{3}{|l|}{ Gender } \\
\hline Male & 16 & 38.1 \\
\hline Female & 26 & 61.9 \\
\hline \multicolumn{3}{|l|}{ Body mass index } \\
\hline$<30$ & 29 & 69 \\
\hline$\geq 30$ & 13 & 31 \\
\hline \multicolumn{3}{|l|}{ ECOG performance status } \\
\hline 0 & 2 & 4.7 \\
\hline 1 & 34 & 81 \\
\hline 2 & 6 & 14.3 \\
\hline \multicolumn{3}{|l|}{ Initial presentation } \\
\hline Swelling & 27 & 64.3 \\
\hline Pain & 9 & 21.4 \\
\hline Limitation of joint mobility & 4 & 9.5 \\
\hline Pathological fracture & 2 & 4.8 \\
\hline \multicolumn{3}{|l|}{ Size of lesion $(\mathrm{cm})$} \\
\hline Median (range) & \multicolumn{2}{|c|}{$11.5(1.5-16)$} \\
\hline$>10$ & 30 & 71.4 \\
\hline$\leq 10$ & 12 & 28.6 \\
\hline \multicolumn{3}{|l|}{ Primary tumor site } \\
\hline Upper limb & 21 & 50 \\
\hline Lower limb & 18 & 42.9 \\
\hline Flat bones & 3 & 7.1 \\
\hline \multicolumn{3}{|l|}{ Lung metastasis at presentation } \\
\hline Yes & 8 & 19 \\
\hline No & 34 & 81 \\
\hline \multicolumn{3}{|l|}{ Denosumab pre-surgery } \\
\hline Yes & 13 & 31 \\
\hline No & 29 & 69 \\
\hline \multicolumn{3}{|c|}{ Response to denosumab pre-surgery } \\
\hline Partial response & 8 & 19 \\
\hline Stable disease & 4 & 9.5 \\
\hline Progressive disease & 1 & 2.4 \\
\hline \multicolumn{3}{|l|}{ Initial surgery } \\
\hline En-bloc or wide resection & 27 & 64.3 \\
\hline Intralesional curettage & 14 & 33.3 \\
\hline No surgery & 1 & 2.4 \\
\hline \multicolumn{3}{|l|}{ Post-surgical residual } \\
\hline Yes & 5 & 11.9 \\
\hline No & 36 & 85.7 \\
\hline \multicolumn{3}{|l|}{ Post-surgical recurrence } \\
\hline Yes & 14 & 33.3 \\
\hline No & 28 & 66.7 \\
\hline \multicolumn{3}{|l|}{ Site of recurrence } \\
\hline Local & 6 & 14.3 \\
\hline Distant & 8 & 19 \\
\hline \multicolumn{3}{|l|}{ Treatment post-recurrence } \\
\hline Denosumab & 12 & 28.6 \\
\hline Surgery & 2 & 4.7 \\
\hline \multicolumn{3}{|c|}{ Response to denosumab post-recurrence } \\
\hline Complete response & 4 & 9.6 \\
\hline Partial response & 2 & 4.8 \\
\hline Stable disease & 4 & 9.6 \\
\hline Progressive disease & 2 & 4.8 \\
\hline
\end{tabular}

ECOG: Eastern Cooperative Oncology Group
The 5-year PFS rate for the whole group of patients was $61 \%$ (Figure 1). For patients who received preoperative denosumab, the 2 and 8 -year PFS were $90 \%$ and $72 \%$, respectively.

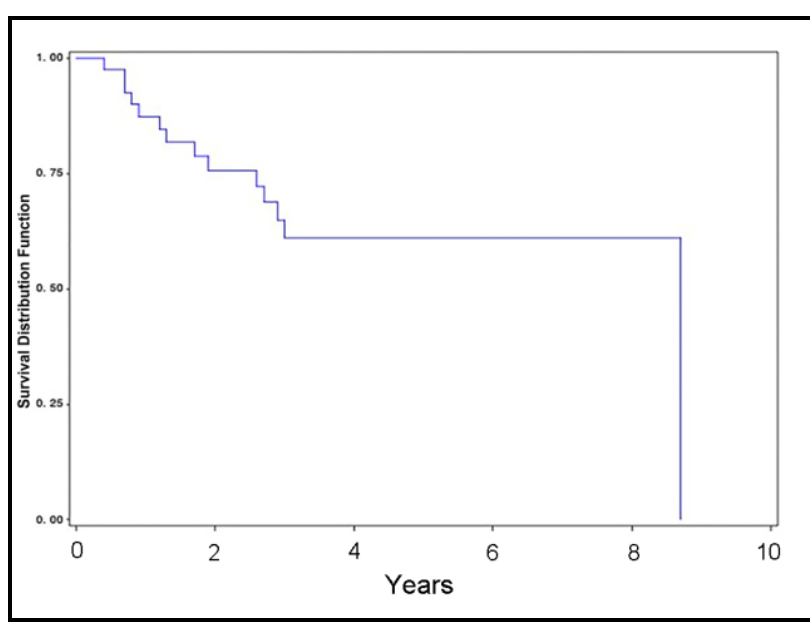

Figure 1: Kaplan Meier curve of PFS for the whole patient group

Table 2 summarizes univariate analysis of PFS according to gender, BMI, primary tumor site and size, first line denosumab, site of recurrence and postrecurrence denosumab.

Table 2: Univariate analysis of progression-free survival according to different prognostic factors

\begin{tabular}{|c|c|c|c|}
\hline \multirow[t]{2}{*}{ Item } & \multicolumn{3}{|c|}{ PFS (years) } \\
\hline & Median & $95 \% \mathrm{CI}$ & p-value \\
\hline \multicolumn{4}{|l|}{ Gender } \\
\hline Male & 8.7 & $1.7-8.7$ & \multirow[t]{2}{*}{0.31} \\
\hline Female & 3.0 & $2.6-\mathrm{NR}$ & \\
\hline \multicolumn{4}{|l|}{ Body mass index } \\
\hline$<30$ & 8.7 & $2.6-8.7$ & \multirow[t]{2}{*}{0.069} \\
\hline$\geq 30$ & 2.9 & $0.8-\mathrm{NR}$ & \\
\hline \multicolumn{4}{|c|}{ Primary tumor site } \\
\hline Upper Limb & 8.7 & $1.7-8.7$ & \multirow[t]{2}{*}{0.253} \\
\hline Lower limb & 3.0 & $1.9-\mathrm{NR}$ & \\
\hline \multicolumn{4}{|l|}{ Size of lesion } \\
\hline$<10 \mathrm{~cm}$ & NR & $2.6-\mathrm{NR}$ & \multirow[t]{2}{*}{0.617} \\
\hline$\geq 10 \mathrm{~cm}$ & 8.7 & $1.3-8.7$ & \\
\hline \multicolumn{4}{|l|}{$\begin{array}{l}\text { Denosumab pre- } \\
\text { surgery }\end{array}$} \\
\hline Yes & 8.7 & $0.9-8.7$ & \multirow[t]{2}{*}{0.413} \\
\hline No & NR & $1.9-\mathrm{NR}$ & \\
\hline \multicolumn{4}{|l|}{ Recurrence } \\
\hline Localized & 2.7 & $0.7-3$ & \multirow[t]{2}{*}{0.069} \\
\hline Metastatic & 1.3 & $0.4-1.9$ & \\
\hline \multicolumn{4}{|c|}{$\begin{array}{l}\text { Denosumab post- } \\
\text { recurrence }\end{array}$} \\
\hline Yes & 2.7 & $0.9-3$ & \multirow[t]{2}{*}{0.035} \\
\hline No & 1.3 & $0.7-1.9$ & \\
\hline
\end{tabular}

PFS: Progression free survival; CI: Confidence interval; NR: Not reached

Patients who received denosumab post-recurrence had longer PFS than those who didn't with statistical significance $(p=0.035 ; 95 \%$ CI: 0.9-3) (Figure 2). Both 
localized recurrence and BMI <30 approached statistical significance as favorable prognostic factors for PFS $(\mathrm{p}=$ 0.069; 95\% CI: $0.7-3$ and $\mathrm{p}=0.069$, 95\% CI: 2.6-8.7; respectively).

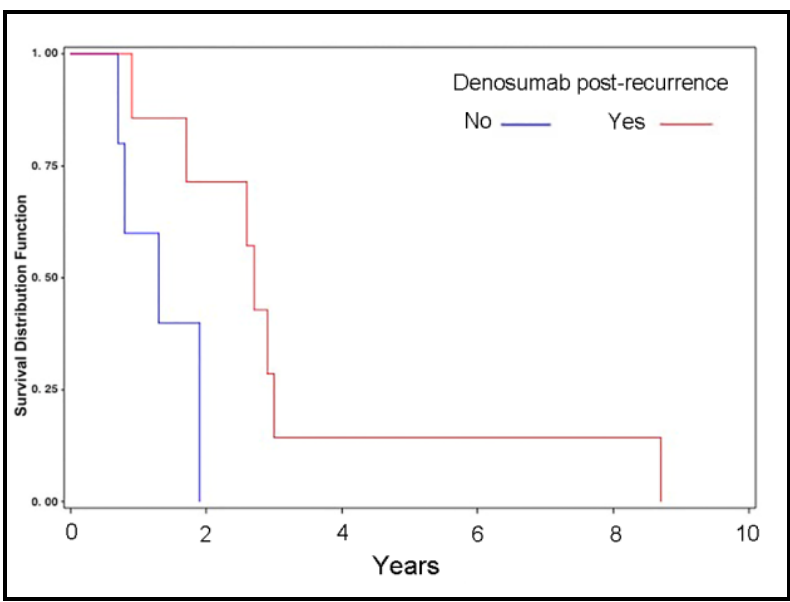

Figure 2: Kaplan Meier curve of progression-free survival in patients who received denosumab postrecurrence vs. those who didn't

Multivariate analysis using Cox regression model was performed. Only denosumab given post-recurrence was found to be of statistical significance for PFS ( $\mathrm{p}=0.034 ;$ 95\% CI: 0.002-0.581) (Table 3).

Table 3: Multivariate analysis of different prognostic factors in the study population

\begin{tabular}{llll}
\hline \multirow{2}{*}{ Item } & \multicolumn{3}{c}{ Progression-free survival } \\
\cline { 2 - 4 } & HR & 95\% CI & p value \\
\hline Body mass index & & & \\
\hline$<\mathbf{3 0}$ & Ref & & \\
\hline$\geq \mathbf{3 0}$ & 1.123 & $0.976-0.129$ & 0.1048 \\
\hline Recurrence site & & & \\
\hline Local & Ref & & \\
\hline Distant & 1.203 & $0.195-7.443$ & 0.8423 \\
\hline $\begin{array}{l}\text { Post-recurrence } \\
\text { denosumab }\end{array}$ & & & \\
\hline No & Ref & & \\
\hline Yes & 0.034 & $0.002-0.581$ & 0.0196 \\
\hline
\end{tabular}

CI: Confidence interval, HR: Hazard ratio

\section{DISCUSSION}

To the best of our knowledge, our study might be considered one of the largest single institutional studies from the Middle East addressing real world experience about managing GCTB taking in consideration the rarity of this disease.

The median age in our study (31.1 years) is comparable to what was reported in most of the literature that showed peak incidence between 20s and 30s 6-8, 25 . Age in our study is younger than what was reported in some retrospective studies. Two retrospective case series from China showed mean age of 39.5 and 35 years versus 32.3 in our study 26, 27. Also, a large epidemiological retrospective study from the data base of the National Rehabilitation Institute, Mexico City had shown mean age of 34.5 years, which is higher than that in our population ${ }^{28}$. On the other hand, the median age of our population cohort was older than what was reported in two retrospective case series showing a median age of 28.2 and 29 years 29,30 .

There is predominance of GCTB in females in our study with a female to male ratio of 1.6: 1 and this is consistent with the literature showing higher incidence of GCTB in females ${ }^{6-8,25,28,29}$.

The median size of primary tumor at initial presentation was $11.5 \mathrm{~cm}$ with $71.4 \%$ of patients having primary tumor size $>10 \mathrm{~cm}$. This relatively large tumor size might explain that enbloc or wide local resection surgery was done in $64.3 \%$ of our patients. This might also explain the post-surgical residual rate of $11.9 \%$ in our patients after initial surgery. A recently published case series from India that included 27 cases of GCTB reported a median size of $6.4 \mathrm{~cm}$ of primary tumors which is smaller than that in our study ${ }^{30}$.

Only $2(4.8 \%)$ patients in the current study had pathological fracture at initial presentation. This is much lower than that described in most of the published data showing that approximately 10 to $35 \%$ of patients present with pathologic fracture because of thinning of the bone cortex especially in weight-bearing areas ${ }^{31-34}$.

Thirteen $(31 \%)$ patients in our study received denosumab as first line treatment before surgery. The optimal number of preoperative denosumab doses is not yet established; our patients received a median of 9 doses (range 4-10). In two recently published studies the median number of preoperative denosumab doses was 6 and 11 respectively ${ }^{35}$. In another study, the median duration of pre-operative denosumab was 12 months (range: 6-45) ${ }^{22}$.

Twelve $(28.5 \%)$ patients in our study had surgery after denosumab with PR in $8(19 \%)$ patients and only 1 (2.4\%) patient showed PD and was exempted from surgery.

Our study showed that the 2 and 8 -year PFS in those who received pre-operative denosumab were $90 \%$ and $72 \%$ respectively. The 2-year PFS was $81 \%$ in a retrospective multicenter analysis of 89 patients with locally advanced or inoperable GCTB patients treated with denosumab outside the context of a clinical trial ${ }^{35}$.

The ORR to denosumab after recurrence in our study was $50 \%$; while in a phase II study, the ORR was $86 \%$ in 37 patients with recurrent or unresectable GCTB treated with denosumab ${ }^{20}$. Lower ORR in our study might be because of lung metastasis noticed in $8(67 \%)$ patients who received denosumab after recurrence.

Denosumab was safe and well tolerated by our patients with no recorded osteonecrosis of jaw (ONJ), hypocalcemia or any other toxicity in all patients who received denosumab either in the preoperative setting or post recurrence.

Data on long-term use of denosumab are available from a retrospective study that included 97 patients, 43 of whom underwent resection after a median time on denosumab treatment of 12 months (range 6 to 45), while 54 had unresectable tumors with a median time on denosumab of 54 months (range 9 to 115$)^{22}$.. In that study, 6 patients developed ONJ. Only patients with 
prolonged treatment experienced mild peripheral neuropathy $(11 \%)$, skin rash $(9 \%)$, hypophosphatemia $(4 \%)$, and atypical femoral fracture $(2 \%)^{22}$.

The limitations of our study include its retrospective nature and the small number of patients who received denosumab. This is because denosumab was approved at our institution after its FDA approval in 2013. On the other hand, its strengths include the long median follow up duration and being one of the largest single institutional studies addressing outcome of this rare disease in this part of the world.

\section{Conclusion}

Our data support the efficacy and tolerability of denosumab in the management of GCTB either preoperatively or post-recurrence. Larger multiinstitutional prospective trials should be done to address denosumab efficacy, optimal duration of treatment, number of cycles especially in the neoadjuvant / preoperative setting and its long term safety profile.

\section{Conflict of interest}

None to declare.

\section{Acknowledgement}

The authors express their appreciation to Ms. Nimeh Shqour, Sarcoma Nurse Coordinator, who helped in the preparation of files and medical records of patients included in this study. Also, they would like to thank members of the Research Data Unit, especially Ms. Tusneem Elhassan who helped in the statistical analysis of data.

\section{REFERENCES}

1. Kim Y, Nizami S, Goto H, Lee FY. Modern interpretation of giant cell tumor of bone: predominantly osteoclastogenic stromal tumor. Clin Orthop Surg. 2012; 4(2):107-116.

2. Behjati S, Tarpey PS, Presneau N, et al. Distinct H3F3A and H3F3B driver mutations define chondroblastoma and giant cell tumor of bone. Nat Genet. 2013; 45(12): 14791482.

3. Amelio JM, Rockberg J, Hernandez RK, et al. Populationbased study of giant cell tumor of bone in Sweden (19832011). Cancer Epidemiol. 2016; 42: 82-89.

4. Guo W, Xu W, Huvos AG, Healey JH, Feng C. Comparative frequency of bone sarcomas among different racial groups. Chin Med J (Engl). 1999; 112(12): 11011104.

5. Sung HW, Kuo DP, Shu WP, Chai YB, Liu CC, Li SM. Giant-cell tumor of bone: analysis of two hundred and eight cases in Chinese patients. J Bone Joint Surg Am. 1982; 64(5): 755-761.

6. Werner M. Giant cell tumour of bone: morphological, biological and histogenetical aspects. Int Orthop. 2006; 30(6): 484-489.

7. Viswanathan S, Jambhekar NA. Metastatic giant cell tumor of bone: are there associated factors and best treatment modalities? Clin Orthop Relat Res. 2010; 468(3): 827-833.

8. Charest-Morin R, Fisher CG, Varga PP, et al. En bloc resection versus intralesional surgery in the treatment of giant cell tumor of the spine. Spine (Phila Pa 1976). 2017;
42(18): 1383-1390

9. Takanami I, Takeuchi K, Naruke M, Kodaira S. Aggressive surgery for treating a pulmonary metastasis of a benign giant cell tumor of the bone: results in four cases. J Thorac Cardiovasc Surg. 1998; 116(4): 649-651.

10. Gresen AA, Dahlin DC, Peterson LF, Payne WS. "Benign" giant cell tumor of bone metastasizing to lung. Ann Thorac Surg. 1973; 16(5): 531-535.

11. Miller IJ, Blank A, Yin SM, McNickle A, Gray R, Gitelis S. A case of recurrent giant cell tumor of bone with malignant transformation and benign pulmonary metastases. Diagn Pathol. 2010; 5: 62.

12. Okamoto Y, Mathew S, Daw NC, et al. Giant cell tumor of bone with pulmonary metastases. Med Pediatr Oncol. 2003; 41(5): 454-459.

13. Guo H, Garcia RA, Perle MA, Amodio J, Greco MA. Giant cell tumor of soft tissue with pulmonary metastases: pathologic and cytogenetic study. Pediatr Dev Pathol. 2005; 8(6): 718-724.

14. Singh AS, Chawla NS, Chawla SP. Giant-cell tumor of bone: treatment options and role of denosumab. Biologics. 2015; 9: 69-74

15. Lin PP, Guzel VB, Moura MF, et al. Long-term follow-up of patients with giant cell tumor of the sacrum treated with selective arterial embolization. Cancer. 2002; 95(6): 1317-1325.

16. Ruka W, Rutkowski P, Morysiński $T$, et al. The megavoltage radiation therapy in treatment of patients with advanced or difficult giant cell tumors of bone. Int J Radiat Oncol Biol Phys. 2010; 78(2): 494-498.

17. Rock MG, Sim FH, Unni KK, et al. Secondary malignant giant-cell tumor of bone. Clinicopathological assessment of nineteen patients. J Bone Joint Surg Am. 1986; 68(7): 1073-1079.

18. Atkins GJ, Haynes DR, Graves SE, et al. Expression of osteoclast differentiation signals by stromal elements of giant cell tumors. J Bone Miner Res. 2000; 15(4): 640649.

19. Branstetter DG, Nelson SD, Manivel JC, et al. Denosumab induces tumor reduction and bone formation in patients with giant-cell tumor of bone. Clin Cancer Res. 2012; 18(16): 4415-4424.

20. Thomas D, Henshaw R, Skubitz K, et al. Denosumab in patients with giant-cell tumour of bone: an open-label, phase 2 study. Lancet Oncol. 2010; 11(3): 275-280.

21. Chawla S, Henshaw R, Seeger L, et al. Safety and efficacy of denosumab for adults and skeletally mature adolescents with giant cell tumour of bone: interim analysis of an open-label, parallel-group, phase 2 study. Lancet Oncol. 2013; 14(9): 901-908.

22. Palmerini E, Chawla NS, Ferrari S, et al. Denosumab in advanced/unresectable giant-cell tumour of bone (GCTB): For how long? Eur J Cancer. 2017; 76: 118-124.

23. Errani C, Tsukamoto S, Mavrogenis AF. How safe and effective is denosumab for bone giant cell tumour? Int Orthop. 2017; 41(11): 2397-2400.

24. Eisenhauer EA, Therasse P, Bogaerts J, et al. New response evaluation criteria in solid tumours: revised RECIST guideline (version 1.1). Eur J Cancer. 2009; 45(2): 228-247.

25. Larsson SE, Lorentzon R, Boquist L. Giant-cell tumor of bone. A demographic, clinical, and histopathological study of all cases recorded in the Swedish Cancer Registry for the years 1958 through 1968. J Bone Joint Surg Am. 1975; 57(2): 167-173.

26. Gong L, Sun X, Meng S, Huang X. Giant cell tumor of bone and malignancies in giant cell tumor: a clinicopathologic analysis. Zhonghua Bing Li Xue Za Zhi. 2009; 38(5): 312-315. 
27. Gong LH, Liu WF, Ding Y, et al. Clinical, radiologic and pathologic features of giant cell tumor of bone treated with denosumab. Zhonghua Bing Li Xue Za Zhi. 2018; 47(6): 449-454.

28. DelaGarza-Montano P, Estrada-Villasenor E, Dominguez Rubio R, et al. Epidemiological aspects of osteosarcoma, giant cell tumor and chondrosarcoma musculoskeletal tumors--experience of the National Rehabilitation Institute, Mexico City. Asian Pac J Cancer Prev. 2015; 16(15): 6451-6455.

29. Tunn P-U, Schlag PM. Giant cell tumor of bone. An evaluation of 87 patients. Z Orthop Ihre Grenzgeb. 2003; 141(6): 690-698.

30. Rekhi B, Verma V, Gulia A, et al. Clinicopathological features of a series of 27 cases of post-denosumab treated giant cell tumors of bones: a single institutional experience at a tertiary cancer referral centre, India. Pathol Oncol Res. 2017; 23(1): 157-164.

31. Enneking WF, Spanier SS, Goodman MA. A system for the surgical staging of musculoskeletal sarcoma. 1980. Clin Orthop Relat Res. 2003; (415):4-18.

32. Campanacci M, Baldini N, Boriani S, Sudanese A. Giantcell tumor of bone. J Bone Joint Surg Am. 1987; 69(1): 106-114.

33. Kivioja AH, Blomqvist $\mathrm{C}$, Hietaniemi $\mathrm{K}$, et al. Cement is recommended in intralesional surgery of giant cell tumors: a Scandinavian Sarcoma Group study of 294 patients followed for a median time of 5 years. Acta Orthop. 2008; 79(1): 86-93.

34. Salunke AA, Chen Y, Chen X, et al. Does pathological fracture affect the rate of local recurrence in patients with a giant cell tumour of bone?: a meta-analysis. Bone Joint J. 2015; 97-B(11): 1566-1571

35. Rutkowski P, Gaston L, Borkowska A, et al. Denosumab treatment of inoperable or locally advanced giant cell tumor of bone - Multicenter analysis outside clinical trial. Eur J Surg Oncol. 2018; 44(9):1384-1390. 